\section{INCREASED INSTITUTIONAL SURGICAL EXPERIENCE IN ROBOT-ASSISTED RADICAL HYSTERECTOMY FOR EARLY STAGE CERVICAL CANCER REDUCES RECURRENCE RATE. RESULTS FROM A NATIONWIDE STUDY}

${ }^{1}$ Linnea Ekdahl, ${ }^{2}$ Emelie Wallin, ${ }^{3}$ Emilia Alfonzo, ${ }^{1}$ Petur Reynisson, ${ }^{1}$ Celine Lönnerfors, ${ }^{3}$ Pernilla Dahm-Kähler, ${ }^{2}$ Henrik Falconer, 'Jan Persson. ' Skåne University Hospital and Lund University Faculty of Medicine; ${ }^{2}$ Karolinska Institutet; ${ }^{3}$ Sahlgrenska Academy at University of Gothenburg

\subsection{6/ijgc-2020-ESG0.206}

Introduction/Background The aim of this study was to evaluate the impact of institutional surgical experience on recurrence following robotic radical hysterectomy (RRH) for early stage cervical cancer.

Methodology All women in Sweden who underwent an RRH for stage IA2-IB1 cervical cancer at tertiary referral centers from its implementation in December 2005 until June 2017 were identified using a Swedish nationwide register and local hospital registers. Registry data was controlled by a chart review on all women. Recurrence rates and pattern of recurrence was compared between early and late ( $\leq 50$ vs $>50$ procedures) institutional series.

Results 635 women were included. Regression analysis identified a lower risk of recurrence with increased experience but without a clear cut off level. Among the 489 women who did not receive adjuvant radio chemotherapy (RC-T), the rate of recurrence was $3.6 \%$ in the experienced cohort $(>50$ procedures) compared to $9.3 \%$ in the introductory cohort $(\mathrm{p}<0.05)$. This was also seen in tumors $<2 \mathrm{~cm}$ regardless of RC-T $(p<0.05)$ whereas no difference in recurrence was seen when analyzing all women receiving RC-T.

Conclusion In conclusion, the rate of recurrence following RRH for early stage cervical cancer decreased with increased institutional surgical experience, in tumors $<2 \mathrm{~cm}$ and in women who did not receive adjuvant RC-T.

Disclosures Jan Persson, Henrik Falconer and Celine Lönnerfors have received honoraria for lectures and proctoring in robotic surgery, all outside the presented research. The other authors have no conflicts of interest.

\section{LONG-TERM RESULTS OF NEOADJUVANT DOSE-DENSE PLATINUM-BASED CHEMOTHERAPY IN PATIENTS WITH LOCALLY ADVANCED CERVICAL CANCER}

${ }^{1}$ Olga Smirnova, ${ }^{2}$ Elena Ulrikh, ${ }^{1}$ Alina Abramova, ${ }^{1}$ Maria Yakovleva, ${ }^{1}$ Anna Petrova, ${ }^{1}$ Nikolay Mikaya, ${ }^{1}$ Olga Lavrinovich, ${ }^{1}$ Nikolay Bondarev, ${ }^{1}$ Adel Urmancheeva, ${ }^{1}$ Igor Berlev. ${ }^{1}$ N.N. Petrov National Medical Research Center of Oncology; ${ }^{2}$ Almazov National Medical Research Centre; North-Western State Medical University, N.N.Petrov National Medical Research Centre of Oncology; Oncology

\subsection{6/ijgc-2020-ESGO.207}

Introduction/Background In our study, we evaluated the longterm results of neoadjuvant dose-dense platinum-based chemotherapy in patients with locally advanced cervical cancer FIGO IB2, IIB stage.

Methodology A cohort of 119 consecutive patients with median age of 43 (range 27-68) years was studied. All patients had verified locally-advanced $\left(\mathrm{cT} 1_{\mathrm{B}} 2 \mathrm{Nx}, 0 \mathrm{M} 0\right.$; $\mathrm{cT} 2{ }_{\mathrm{B}} \mathrm{Nx}, 0 \mathrm{M} 0$ ) cervical cancer and received 3 dose-dense intravenous neoadjuvant AP (cisplatin $75 \mathrm{mg} / \mathrm{m} 2$, doxorubicin 35 $\mathrm{mg} / \mathrm{m} 2 ; \mathrm{n}=75$ ) or TP (cisplatin $60 \mathrm{mg} / \mathrm{m} 2$ and paclitaxel 60 $\mathrm{mg} / \mathrm{m} 2 ; \mathrm{n}=30$ ) chemotherapy cycles.
Results The median follow-up was 28 (4 - 48) months for AP and 17 (3 - 30) months for TP group, accordingly. The overall survival rates in FIGO IB2 stage for AP and TP groups were $100 \%$. For FIGO IIB stage the overall survival rate in AP group was 94\%, in TP group - 97\%.

The disease-free survival rate in FIGO IB2 stage for AP group was $78 \%$, for TP group - 100\%. For FIGO IIB stage the disease-free survival rate in the AP group was $87 \%$, in $\mathrm{TP}$ group - $100 \%$.

Conclusion The dose-intensive chemotherapy is an effective treatment modality for locally-advanced cervical cancer and may be a feasible alternative for standard treatment approach. It deserves further study in larger patient cohort with evaluation of the long-term results.

\section{COMPARISON OF TOPICAL TREATMENT OF CERVICAL SQUAMOUS INTRAEPITHELIAL LESIONSWITH IMIQUIMOD WITH STANDARD EXCISIONAL TECHNIQUE USING LLETZ: A RANDOMIZED CONTROLLED TRIAL}

${ }^{1}$ Andrej Cokan, ${ }^{1}$ Maja Pakiž, ${ }^{1} J u r e ~ K n e z, ~{ }^{1}$ Andraž Dovnik, ${ }^{1}$ Tatjana Kodrič, ${ }^{1}$ Leyla Al Mahdawi, ${ }^{2}$ Tamara Serdinšek, ${ }^{3}$ Alenka Repše Fokter, ${ }^{1}$ Igor But. ${ }^{1}$ Umc Maribor; Department for Gynaecologic Oncology and Oncology of the Breast; ${ }^{2}$ Umc Maribor: Department for General Gynaecology and Gynaecologic Urology; ${ }^{3}$ Medical Faculty Maribor; Gh Celje

\subsection{6/ijgc-2020-ESG0.208}

Introduction/Background Standard treatment of cervical squamous intraepithelial lesions (SIL) is large loop excision of transformation zone (LLETZ), which is associated with increased risk of preterm delivery, higher subfertility rate, and higher spontaneous abortions rate. Our aim was to determine whether topical treatment of high-grade SIL (HSIL) with imiquimod is comparable to standard treatment in terms of efficiency and side effects occurrence.

Abstract 608 Table 1 Succces of treated in patient treated with imiquimod (group 1) and LLETZ (group 2)

\begin{tabular}{|c|c|c|c|}
\hline & $\begin{array}{l}\text { Group 1 } \\
\text { (Imiquimod) }\end{array}$ & $\begin{array}{l}\text { Group 2 } \\
\text { (LLETZ) }\end{array}$ & p-value \\
\hline CIN 2 [N/total N (\%)] & $17 / 21(81.0)$ & $12 / 19(63.2)$ & 0.366 \\
\hline CIN 3 [N/total N (\%)] & $10 / 22(45.5)$ & $27 / 33(81.8)$ & $0.012^{*}$ \\
\hline All patients [N/total N (\%)] & $27 / 43(62.8)$ & $39 / 52(75.0)$ & 0.288 \\
\hline
\end{tabular}

Abstract 608 Table 2 Presence of side effects and the highest grade of side effects in patients treated with imiquimod (group 1) and LLETZ (group 2)

\begin{tabular}{|c|c|c|c|c|}
\hline & & $\begin{array}{l}\text { Group } 1 \\
\text { (Imiquimod) }\end{array}$ & $\begin{array}{l}\text { Group } 2 \\
\text { (LLETZ) }\end{array}$ & p-value \\
\hline \multicolumn{2}{|c|}{$\begin{array}{l}\text { Side effects: yes } \\
{[\mathrm{N} / \text { total } \mathrm{N}(\%)]}\end{array}$} & $\begin{array}{l}46 / 52 \\
(88.5 \%) \\
\end{array}$ & $\begin{array}{l}23 / 52 \\
(44.2) \\
\end{array}$ & $<0.001^{*}$ \\
\hline \multirow{4}{*}{$\begin{array}{l}\text { Highest } \\
\text { grade of } \\
\text { side effect } \\
\text { [N/total } N \\
(\%)]\end{array}$} & Grade 1 & $18 / 52(34.6)$ & $\begin{array}{l}14 / 52 \\
(26.9) \\
\end{array}$ & \multirow[t]{4}{*}{$<0.001^{*}$} \\
\hline & Grade 2 & $20 / 52(38.5)$ & $7 / 25(13.5)$ & \\
\hline & Grade 3 & $7 / 52(13.5)$ & $0 / 52(0)$ & \\
\hline & Other & $1 / 52(1.9)$ & $2 / 52(3.8)$ & \\
\hline
\end{tabular}

*Statistically significant difference. 